\section{Hypocupremia and bone marrow failure}

Copper deficiency associated with neurological disorders is a well-documented condition. However, hypocupremia is less often recognized as a cause of cytopenias or bone marrow failure. We report an illustrative series of three new cases of bi-lineage cytopenia associated with copper deficiency. We have analyzed clinical features of current and historical cases to identify clues that could facilitate application of appropriate laboratory testing and heighten the level of clinical suspicion. By maintaining an appropriately high level of suspicion for potential copper deficiency and obtaining a serum copper level, bone marrow failure due to this condition can be correctly diagnosed and treated. We suggest that copper deficiency be included in the differential diagnosis of reversible causes of bone marrow failure syndromes including myelodysplastic syndrome.

Haematologica 2008; 93:e1-e5 D0I: 10.3324/haematol.12121

\section{Introduction}

In the evaluation of patients with pancytopenia, reversible causes of bone marrow failure such as nutritional deficiencies, viral infections, and medications need to be considered in the differential diagnosis. Copper deficiency can be easily treated but the diagnosis may be difficult due to comorbidities and low level of clinical suspicion.

Patients with copper deficiency most commonly present with neurological disorders, including myeloneuropathy, arthralgias and neuropathy. ${ }^{1-4} \mathrm{~A}$ diagnosis of copper deficiency is usually established by measuring serum copper or ceruloplasmin levels; a serum copper level $<10 \propto \mathrm{mol} / \mathrm{L}$ or ceruloplasmin $<180 \mathrm{mg} / \mathrm{L}$ is considered presumptive evidence of copper deficiency. The most common hematologic abnormalities associated with copper deficiency include anemia and neutropenia, while the platelet count usually remains normal.

The adult diet in Western countries contains 0.6 to 1.6 $\mathrm{mg}$ of copper/d. Water, shellfish, organ meats, nuts, and grains are all sources of dietary copper. Absorption occurs through the intestinal mucosa across the basement membrane into the blood stream via energy dependent mechanisms where the availability and saturation of copper may limit absorption. Of significant interest is the physiologic relationship between copper and zinc. High zinc levels result in increased metallothionin production in enterocytes. The high affinity of copper to metallothionin displaces zinc and thus leads to the accumulation of copper in the enterocytes. The enterocytes are ultimately shed into the gastrointestinal tract, leading to copper elimination. ${ }^{5}$

Copper plays a role as a cofactor for many enzymes, in electron-transporting proteins, and in antioxidant metabolism. The main copper-binding protein is ceruloplasmin which plays a role in copper transport and release and in protection of cells from oxidative damage. Both ferroxi-
Table 1. Clinical characteristics of patients with cytopenias due to copper deficiency.

\begin{tabular}{|c|c|c|c|}
\hline Parameter & Case \#1 & Case \#2 & Case \#3 \\
\hline Age/Sex & $60 / F$ & $38 / F$ & $53 / M$ \\
\hline $\begin{array}{l}\text { Malabsorption } \\
\text { history? }\end{array}$ & Yes, pancreatitis & Yes, gastric bypass & No \\
\hline Neuropathy? & Yes (severe) & Yes (mild) & Yes (mild) \\
\hline $\begin{array}{l}\text { Absolute neutrophil } \\
\text { count } \times 10^{9} / \mathrm{L}\end{array}$ & 0.170 & 0.240 & 1.72 \\
\hline Hemoglobin (g/L) & 85 & 72 & 100 \\
\hline MCV (fL) & 95.7 & 94.1 & 99.3 \\
\hline Platelets x109/L & 335 & 196 & 197 \\
\hline $\begin{array}{l}\text { Bone marrow } \\
\text { cellularity }\end{array}$ & Normocellular & Hypocellular & Not performed \\
\hline $\begin{array}{l}\text { Serum zinc } \\
\mathrm{N}(8.4-22.9 \mu \mathrm{mol} / \mathrm{L})\end{array}$ & 14.9 & 12.4 & 33.5 \\
\hline $\begin{array}{l}\text { Serum copper } \\
(13-24 \mu \mathrm{mol} / \mathrm{L})\end{array}$ & $<2$ & & $<2$ \\
\hline
\end{tabular}

dase and ceruloplasmin may oxidize $\mathrm{Fe}^{2+}$ to $\mathrm{Fe}^{3+}$ facilitating the release of Fe from ferritin and its binding to transferrin. ${ }^{6}$ Copper is required for a variety of enzymes, including amino oxidase, ferroxidase, cytochrome-C- oxidase and dopamine hydroxylase. Copper is a cofactor for cytochrome oxidase, methallothionein and superoxide dismutase (SOD) involved in antioxidative responses. ${ }^{6-8}$

The mechanism by which copper deficiency results in cytopenias is not well understood. In general, many copper-containing proteins are important for the proper function of the hematopoietic system. Copper deficiency decreases transferrin concentration in the plasma, and facilitates heme degradation secondary to an increase in heme oxygenase. Copper deficiency may result in a reduction in of cytochrome-C-oxidase, leading to a slower rate of electron flow and ATP production, and ultimately diminished hemoglobin synthesis. Ceruloplasmin and copper-zinc SOD are decreased in copper deficiency, affecting the survival of erythrocytes.

This report was inspired by the clinical observation of 3 very informative cases of copper deficiency associated with cytopenia (Table 1).

\section{Patients and literature}

Case 1. A 60-year-old woman presented with an unexplained $80 \mathrm{lb}$ weight loss over 4 months. She complained of discomfort and numbness in her fingertips and loss of sensation in her hands; she noted similar symptoms involving her lower extremities. She had gradually developed progressive gait abnormalities and eventually became wheelchair bound. Her past medical history included pernicious anemia, pancreatitis, and a cholecystectomy; there was no history of alcohol abuse. The patient had been treated for pernicious anemia without response. Physical exam showed mild weakness in both legs that was attributed to leg pain, reduced sensation to pain up to the anterior thighs bilaterally, 
and impaired vibratory sensation up to her knees. Proprioception was impaired in the feet and the ankles. Her gait was wide-based. MRI of the brain and spine were normal. Laboratory studies showed a normocytic anemia with hemoglobin as low as $86 \mathrm{~g} / \mathrm{L}$, reticulocyte count of $1.6 \%$, WBC: $1.5 \times 10^{9} / \mathrm{L}$ with absolute neutropenia $\left(0.130 \times 10^{9} / \mathrm{L}\right)$, and a normal serum vitamin B12 level, normal methylmalonic acid level, negative HTLVI serology, and negative heavy metal screen including arsenic, mercury and lead. Initial and repeat bone marrow biopsies were unremarkable with normal cellularity (Figure 1). Virtually no plasma cells were present in the aspirate smear. Based on the combination of the pancytopenia and the neurologic signs and symptoms copper deficiency was suspected. Serum copper was $<2$ $\propto \mathrm{mol} / \mathrm{L}$ (normal: 13-24), ceruloplasmin level was 20 $\mathrm{mg} / \mathrm{L}$ (normal: 210-450), and $24 \mathrm{hr}$ urine for copper was $2 \mathrm{ug} / 24 \mathrm{hrs}$ (normal 0-40). A diagnosis of copper deficiency was made, and the patient was treated with $2 \mathrm{mg}$ oral copper twice daily; the dose was subsequently increased to $6 \mathrm{mg}$ taken three times a day. She showed an excellent hematologic response approximately 6 months after starting treatment. Neurological symptoms stabilized with minimal improvement.

Case 2. A 38-year-old woman who had a gastric bypass operation four years earlier presented for evaluation of unsuspected anemia found when volunteering to become a blood donor. Upon further questioning, the patient admitted to symptoms of fatigue for more than a month, lightheadedness and dizziness. She had numbness in the distal part of her legs for a few months. She did not have any other significant past medical history or any other symptoms. Current medications included Mometasone Furoate, loratadine, zinc, calcium, prenatal vitamins, ester-CYP3A4, vitamin B12, vitamin B6, and ferrous sulfate. The physical examination was unremarkable. A blood cell count showed WBC: $1.3 \times 10^{9} / \mathrm{L}$ (normal: 4.0-11.0), Hgb: $72 \mathrm{~g} / \mathrm{L}$ (normal: 120-160), MCV 94.1 fL (Normal: 80-100), and platelet count: 196x10\%/L (normal 150-400) (Table 1). There was severe neutropenia $\left(0.240 \times 10^{\circ} / \mathrm{L}\right)$. Ferritin, vitamin B12, folic acid, and TSH were within normal limits. Additional laboratory studies showed serum copper: $<2 \propto \mathrm{mol} / \mathrm{L}$ (normal: 1324) and serum zinc: $<12.4 \propto \mathrm{mol} / \mathrm{L}$ (normal: 8.4-22.9). Bone marrow aspirate and biopsy were slightly hypocellular for age $(40 \%)$ with trilineage hematopoiesis, an erythroid predominance, and mild megakaryocytic hyperplasia. Bone marrow aspirate smears demonstrated multiple clear cytoplasmic vacuoles in proerythroblasts, also plasma cells containing hemosiderin pigment were present (Figure 1). A diagnosis of copper deficiency was established, and she was treated with oral copper $2 \mathrm{mg}$ twice daily. After 3 months a blood cell count showed: WBC: $7.55 \times 10^{\circ} / \mathrm{L}, \mathrm{Hgb}: 134 \mathrm{~g} / \mathrm{L}$, absolute neutrophil count: $4.27 \times 10^{9} / \mathrm{L}$ and serum copper: $17 \propto \mathrm{mol} / \mathrm{L}$. Her neurologic symptoms completely resolved.
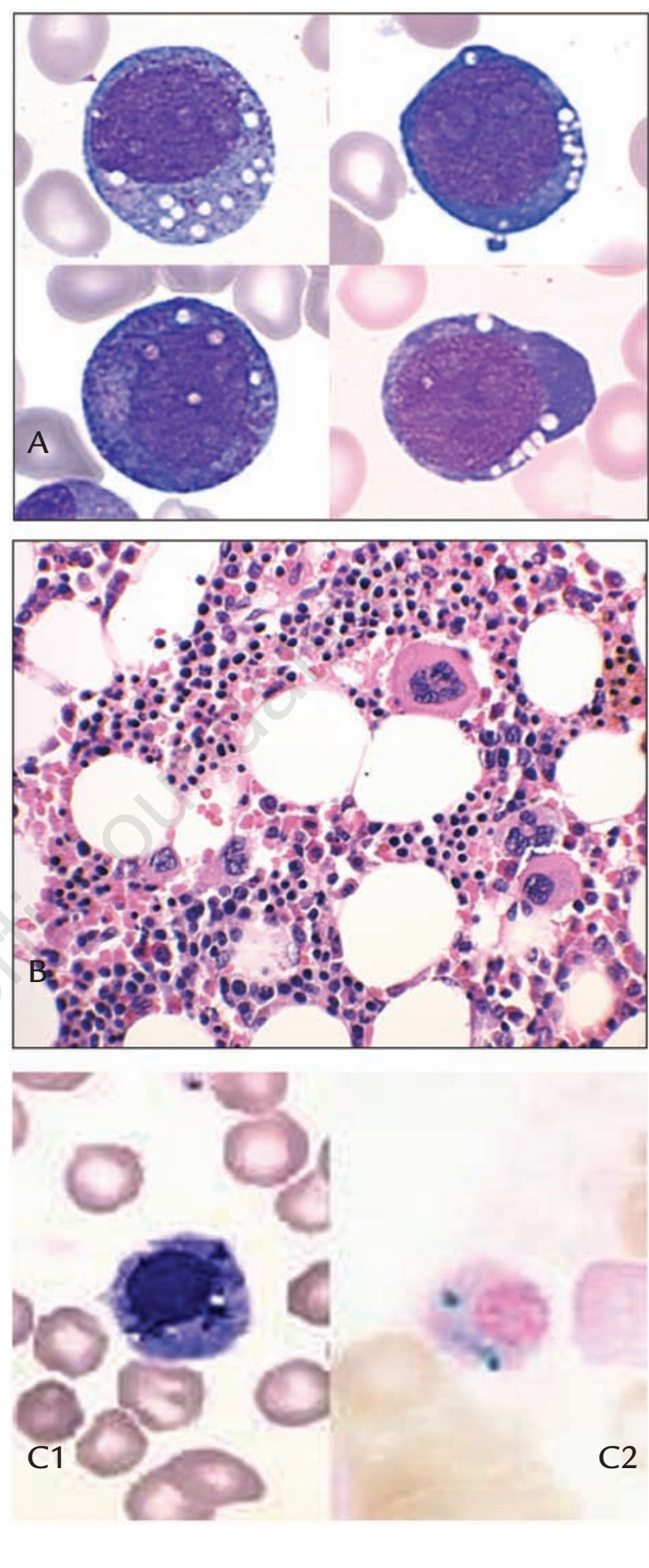

Figure 1. Morphology of bone marrow in copper deficiency. (A) Bone marrow aspirate smears demonstrated multiple clear cytoplasmic vacuoles in promyelocytes (left panels) and proerythroblasts (right panels) from Case 1 (bottom panels) and Case 2 (top panels). Vacuolated cells were infrequent in both cases, and significant dysplastic features were not identified in either case. (Wright-Giemsa stain, original magnification 100x). (B) Bone marrow biopsy from Case 2 was slightly hypocellular for age $(40 \%)$ with trilineage hematopoiesis, an erythroid predominance, and mild megakaryocytic hyperplasia. (H\&E stain, original magnification 40x). (C) Hemosiderin (iron) containing plasma cells were noted in case 2 . In the marrow aspirate approximately $25 \%$ of plasma cells contained cytoplasmic hemosiderin pigment (C1) that was highlighted in iron stain (C2). ( $\mathrm{H}+\mathrm{E}$ stain and pression stains, orginal magnification 100X). 
Case \#3. A 53-year-old man presented with anemia, leukopenia and neurological symptoms (Table 1). His symptoms started five years prior to presentation with numbness in his feet; this was followed by progressive foot and hand weakness to the extent that he developed bilateral foot and wrist drop. His past medical history was significant for gastroesophageal reflux disease, frequent alcohol and tobacco use, and chronic normocytic anemia and leukopenia. Physical examination was negative except for bilateral weakness in the wrists and feet, and reduced pinprick sensation from toes to ankles and from fingers to wrists; vibratory sensation was absent at toes and ankles. Laboratory studies showed: WBC: $2.32 \times 10^{9} / \mathrm{L}$ (normal: 4.0-11), Hgb: $100 \mathrm{~g} / \mathrm{L}$ (normal: 135-175), MCV: $99.3 \mathrm{fL}$ (normal: 80-100), platelets: 197x10\%/L (normal: 150-400), and absolute neutrophil count: $1.72 \times 10^{9} / \mathrm{L}$. Additional studies showed serum zinc: $33.5 \propto \mathrm{mol} / \mathrm{L}$ (normal: 8.4-22.9), $24 \mathrm{hr}$ zinc excretion: $4,940 \mathrm{ug} / 24 \mathrm{hr}$ (normal: $150-1300$ ), serum copper: $<2 \propto \mathrm{mol} / \mathrm{L}$ (normal: 13-24), and serum ceruloplasmin: $40 \mathrm{mg} / \mathrm{L}$ (normal: 21-45). He was treated with oral copper $(2 \mathrm{mg}$ twice daily which was increased to $5 \mathrm{mg}$ twice daily until the present time. Five months later his blood cell count and copper level normalized, but zinc level continued to be above the normal level.

Summary of previous cases. Systematic review of the literature from 1985 to 2005 was performed and identified 45 reported patients with severe copper deficiency in addition to our three cases (Table 2). Of these, 47 (98\%) had absolute neutropenia, $48(100 \%)$ had anemia, and thrombocytopenia was seen in $5(10 \%)$. The anemia was microcytic in only $2(4 \%)$ and macrocytic in 17 (35\%). The serum copper level was low in 47 (98\%) patients. All patients were reported to be recovered either following copper supplementation or discontinuing zinc (if the copper deficiency was due to increased zinc ingestion). Twenty patients ( $41 \%$ ) had documented neurological findings ranging from polyneuropathy, loss of sensation in the extremities, loss of vibratory sensation, sensory ataxia without involvement of cerebellum, gait abnormalities with wide-based gait, increased tone, weakness, exaggerated reflexes, loss of Babinski's reflex and neurocognitive defects. Importantly, hematologic abnormalities due to copper deficiency were not always associated with neurologic symptoms. Available bone marrow findings revealed cytoplasmic vacuolization in 27 patients $(56 \%)$, refractory anemia with ringed sideroblasts (RARS) in 22/48 (41\%), and 12/48 (25\%) had a hypocellular bone marrow (Table 3 ).

\section{Discussion}

The neurological symptoms of copper deficiency are well-defined. However, copper deficiency is only rarely recognized as a cause of pancytopenia. The causative relationship between decreased copper level and pancytopenia can be inferred from the excellent response to treatment with copper supplementation.

\begin{tabular}{|c|c|c|c|c|c|c|c|c|c|c|c|}
\hline$\#$ & Reference & $\begin{array}{l}\text { \# of } \\
\text { Cases }\end{array}$ & CNS & $H b$ & MCV & ANC & Platelets & $\begin{array}{l}\text { Cytoplasmic } \\
\text { vacuolization? }\end{array}$ & $\begin{array}{l}\text { Ringed } \\
\text { sideroblast? }\end{array}$ & $\downarrow$ Cellularity & $\begin{array}{l}\text { Response } \\
\text { to copper? }\end{array}$ \\
\hline 1 & 23 & 1 & No & & Low & $\downarrow$ & $\mathrm{NL}$ & $\mathrm{N}$ & $\mathrm{N}$ & $\mathrm{N}$ & $Y$ \\
\hline 2 & 10 & 5 & Yes & & $\mathrm{NL}$ & $\downarrow$ & $\mathrm{NL}$ & $\mathrm{N} / \mathrm{A}$ & $\mathrm{N} / \mathrm{A}$ & $\mathrm{N} / \mathrm{A}$ & $Y$ \\
\hline 3 & 20 & 1 & Yes & & $\mathrm{NL}$ & $\downarrow$ & $\mathrm{NL}$ & $\mathrm{N} / \mathrm{A}$ & $\mathrm{N} / \mathrm{A}$ & N/A & $Y$ \\
\hline 4 & 15 & 3 & Yes & & $\mathrm{NL}$ & $\downarrow$ & $\mathrm{NL}$ & $Y^{\prime}$ & $Y^{\prime}$ & $Y^{\prime}$ & $Y$ \\
\hline 5 & 5 & 1 & Yes & 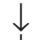 & High & $\downarrow$ & $\mathrm{N} / \mathrm{A}$ & $\mathrm{N}$ & $\mathrm{N}$ & $\mathrm{N}$ & Zn stop \\
\hline 6 & 12 & 1 & Yes & & $\mathrm{NL}$ & $\downarrow$ & High & $\mathrm{N}$ & Y & Y & \\
\hline 7 & 29 & 1 & Yes & $\downarrow$ & High & $\downarrow$ & $\mathrm{NL}$ & $\mathrm{N} / \mathrm{A}$ & $\mathrm{N} / \mathrm{A}$ & $\mathrm{N} / \mathrm{A}$ & Zn stop \\
\hline 8 & 27 & 1 & Yes & & N/A & $\downarrow$ & Low & $\mathrm{N}$ & $\mathrm{N}$ & N & Y \\
\hline 9 & 25 & 1 & Yes & $\downarrow$ & High & $\downarrow$ & NL & Y & Y & $\mathrm{N}$ & Zn stop \\
\hline 10 & 30 & 1 & Yes & $\downarrow$ & $\mathrm{NL}$ & $\mathrm{N} / \mathrm{A}$ & $\mathrm{N} / \mathrm{A}$ & $\mathrm{N} / \mathrm{A}$ & $\mathrm{N} / \mathrm{A}$ & $\mathrm{N} / \mathrm{A}$ & Y \\
\hline 11 & 22 & 1 & Yes & $\downarrow$ & High & $\downarrow$ & NL & $Y^{\prime}$ & $Y^{\prime}$ & $\mathrm{N}$ & $Y$ \\
\hline 12 & 26 & 1 & Yes & 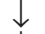 & High & $\downarrow$ & $\mathrm{NL}$ & Y & Y & Y & $Y$ \\
\hline 13 & 19 & 1 & $\mathrm{~N} / \mathrm{A}$ & & N/A & $\downarrow$ & Low & Y & $\mathrm{N}$ & Y & Y \\
\hline 14 & 18 & 1 & $\mathrm{~N} / \mathrm{A}$ & 1 & N/A & $\downarrow$ & Low & Y & $\mathrm{N}$ & Y & Y \\
\hline 15 & 28 & 1 & $\mathrm{~N} / \mathrm{A}$ & $\downarrow$ & Low & $\downarrow$ & NL & Y & Y & $\mathrm{N}$ & Y \\
\hline 16 & 11 & 6 & $\mathrm{~N} / \mathrm{A}$ & 1 & N/A & $\downarrow$ & $\mathrm{NL}$ & $\mathrm{N} / \mathrm{A}$ & $\mathrm{N} / \mathrm{A}$ & $\mathrm{N} / \mathrm{A}$ & Y \\
\hline 17 & 9 & 10 & No & & High & $\downarrow$ & $\mathrm{NL}$ & $Y \times 6$ & $Y \times 6$ & Y & Zn stop \\
\hline 18 & 17 & 1 & No & t & N/A & $\downarrow$ & Low & $\mathrm{N} / \mathrm{A}$ & $\mathrm{N} / \mathrm{A}$ & $\mathrm{N} / \mathrm{A}$ & Y \\
\hline 19 & 24 & 1 & No & $\downarrow$ & $\mathrm{NL}$ & $\downarrow$ & $\mathrm{NL}$ & $Y^{\prime}$ & $Y^{\prime}$ & $\mathrm{N}$ & Y \\
\hline 20 & 31 & 1 & No & $\downarrow$ & $\mathrm{NL}$ & $\downarrow$ & $\mathrm{NL}$ & Y & Y & $Y$ & $Y$ \\
\hline 21 & 14 & 2 & No & $\downarrow$ & N/A & $\downarrow$ & NL & $Y$ & $Y$ & Y & Zn stop \\
\hline 22 & 13 & 1 & No & $\downarrow$ & High & $\downarrow$ & $\mathrm{NL}$ & Y & $Y$ & $\mathrm{~N} / \mathrm{A}$ & Zn stop \\
\hline 23 & 21 & 1 & No & $\downarrow$ & N/A & $\downarrow$ & NL & $\mathrm{N} / \mathrm{A}$ & $\mathrm{N} / \mathrm{A}$ & $\mathrm{N} / \mathrm{A}$ & Y \\
\hline 24 & 16 & 1 & Yes & $\downarrow$ & NL & $\downarrow$ & Low & $Y^{\prime}$ & $Y^{\prime}$ & $\mathrm{N}$ & Y \\
\hline 25 & Our Case \#1 & 1 & Yes & $\downarrow$ & $\mathrm{NL}$ & $\downarrow$ & $\mathrm{NL}$ & Y & Y & $\mathrm{N}$ & Y \\
\hline 26 & Our Case \#2 & 1 & Yes & $\downarrow$ & $\mathrm{NL}$ & $\downarrow$ & NL & $Y$ & Y & Y & Y \\
\hline 27 & Our Case \#3 & 1 & Yes & $\downarrow$ & High & $\downarrow$ & NL & $\mathrm{N} / \mathrm{A}$ & $\mathrm{N} / \mathrm{A}$ & $\mathrm{N} / \mathrm{A}$ & Y \\
\hline
\end{tabular}


Table 3. Review of MCV, ANC, platelet count and pathologic abnormalities in copper deficiency.

\begin{tabular}{llllll}
\hline Total n. of cases & No. of pts. with anemia & MCV & ANC & Platelet & $\begin{array}{l}\text { Pathologic abnormalities } \\
\text { in bone marrow }\end{array}$ \\
\hline 48 & $48(100 \%)$ & NL 16/48 (335) & Low 47/48 (98\%) & Low 5/48 (10\%) & $\begin{array}{l}\text { Cytoplasmic Vacuolization } \\
23 / 48(48 \%)\end{array}$ \\
& High 17/48 (355) & N/A 1/48 (2\%) & High 1/48 (2\%) & $\begin{array}{l}\text { Ringed sideroblasts } \\
22 / 48(41 \%)\end{array}$ \\
& Low 2/48 (4\%) & & Normal 40/48 (83\%) & $\begin{array}{l}\text { Hypocellularity } \\
12 / 48(255)\end{array}$ \\
& Unknown 13/48 (27\%) & Unknown 2/48 (4\%) &
\end{tabular}

MCV, mean corpuscular volume; ANC, absolute neutrophil count; $N L$, normal; $N / A$, not available.

Our three well annotated cases of copper deficiency are very illustrative and serve to highlight the main features that may trigger targeted diagnostic tests to exclude copper deficiency as a cause of cytopenias. Historically, 48 cases of copper deficiency, including three from our institution, were associated with hematologic abnormalities. The largest single series of published cases included "10 patients. ${ }^{9}$ All reported cases of copper deficiency showed anemia and absolute neutropenia. MCV values were variable, and ranged from low to high. Thrombocytopenia was absent in most cases, aside from patients receiving total parenteral nutrition. A rarely noted finding is the presence of prominent hemosiderin in plasma cells. ${ }^{26}$ The majority of patients showed an improvement in their $\mathrm{CBC}$ or a complete hematologic response following either therapy with copper supplements or by eliminating excess dietary zinc or zinc supplements. ${ }^{10-12}$

Multiple reports have implicated low copper levels in the pathogenesis of selected cases of refractory anemia with ringed sideroblasts (RARS) responsive to copper; all cases had normal platelet counts. ${ }^{13-15}$ Refractory sideroblastic anemia was reported in 22 patients, and often occurred in association with excessive zinc ingestion, a finding causally linked to decreased copper levels. Stopping zinc supplements or removing dietary sources of excess zinc was enough to achieve hematologic recovery in these patients. Less well characterized and more loosely associated were cytopenia and myeloneuropathy are signs and symptoms of copper deficiency were highlighted in several case reports. ${ }^{1,2,16-20}$ The most common causes of copper deficiency are malabsorption and malnutrition, but as noted above, copper deficiency can also occur secondary to chronic use of large doses of zinc causing zinc overload syndrome. ${ }^{21,22}$ Responsive to copper supplementation or zinc withdrawal in cases the diagnosis of RARS should be avoided, since the anemia is not refractory to treatment and true myelodysplastic syndrome is not present.

Chronic copper overdose, which is a very rare condition, may cause serious side effects including liver cirrhosis, episodes of hemolysis and kidney damage, and even death.

In conclusions our study demonstrates that copper and zinc levels should be checked in patients who pres- ent with cytopenias, especially in cases lacking thrombocytopenia, or having vacuolated erythroid precursors in a marrow aspirate, or with increased RS. Copper deficiency usually presents with bicytopenia (neutropenia and anemia), but severe pancytopenia has been observed in some cases, especially those patients on TPN. Hematologic recovery can be achieved with oral copper supplements administered for a few weeks, but some patients may require supplementation using total parenteral infusions. In cases of hyperzincemia or zinc overdose, discontinuing the zinc supplementation can be sufficient for hematologic recovery.

\section{A.S. Haddad, 1,2 V. Subbiah, ${ }^{1,4}$ A.E. Lichtin, K.S. Theil, J.P. Maciejewski,}

${ }^{1}$ Experimental Hematology and Hematopoiesis Section; ${ }^{2}$ Department of Hematologic Oncology and Blood Disorders; Taussig Cancer Center; ${ }^{3}$ Department of Clinical Pathology, Section of Hematopathology; Cleveland Clinic, Cleveland, OH;

${ }^{4}$ Department of Internal Medicine/Pediatrics, Case Western Reserve University, Cleveland, OH, USA

Supported in part by R01 655365071402, U54-655365070704, K24 655365071503, grant from the Aplastic Anemia and MDS International Foundation NIH (to JPM).

Key words: copper deficiency, hypocupremia, bone marrow failure Correspondence: Jaroslaw Maciejewski, $M D, P h D$, Experimental Hematology and Hematopoiesis Section, Taussig Cancer Center, Cleveland Clinic Foundation, 9500 Euclid Avenue, R40, Cleveland, Ohio 44195 USA. Phone: +1.216-445-5962. Fax +1.216-6362495.E-mail:maciejj@ccf.org

\section{References}

1. Kumar N, Low PA. Myeloneuropathy and anemia due to copper malabsorption. J Neurol 2004; 251:747-9

2. Schleper B, Stuerenburg HJ. Copper deficiency-associated myelopathy in a 46-year-old woman. J Neurol 2001; 248:705-6

3. Kumar N. Copper deficiency myelopathy (human swayback). Mayo Clin Proc 2006; 81:1371-84

4. Kumar N, Gross JB, Jr., Ahlskog JE. Copper deficiency myelopathy produces a clinical picture like subacute combined degeneration. Neurology 2004; 63:33-9

5. Rowin J, Lewis SL. Copper deficiency myeloneuropathy and pancytopenia secondary to overuse of zinc supplementation. J Neurol Neurosurg Psychiatry 2005; 76:750-1

6. Linder MC, Hazegh-Azam M. Copper biochemistry and molecular biology. Am J Clin Nutr 1996; 63:797S-811S

7. Rossi L, Arciello M, Capo C, et al. Copper imbalance and oxidative stress in neurodegeneration. Ital J Biochem 2006; 55:212-21

8. Madsen E, Gitlin JD. Copper deficiency. Curr Opin Gastroenterol 2007; 23:187-92 
9. Fiske DN, McCoy HE, 3rd, Kitchens CS. Zinc-induced sideroblastic anemia: report of a case, review of the literature, and description of the hematologic syndrome. Am J Hematol 1994; 46:147-50

10. Nagano $T$, Toyoda $T$, Tanabe $H$, et al. Clinical features of hematological disorders caused by copper deficiency during long-term enteral nutrition. Intern Med 2005; 44:554-9

11. Banno S, Niita M, Kikuchi M, et al. [Anemia and neutropenia in elderly patients caused by copper deficiency for long-term enteral nutrition]. Rinsho Ketsueki 1994; 35:1276-81

12. Kumar N, Elliott MA, Hoyer JD, et al. "Myelodysplasia," myeloneuropathy, and copper deficiency. Mayo Clin Proc 2005; 80:943-6

13. Simon SR, Branda RF, Tindle BF, et al. Copper deficiency and sideroblastic anemia associated with zinc ingestion. Am J Hematol 1988; 28:181-3

14. Broun ER, Greist A, Tricot G, et al. Excessive zinc ingestion. A reversible cause of sideroblastic anemia and bone marrow depression. JAMA 1990; 264:1441-3

15. Willis MS, Monaghan SA, Miller ML, et al. Zinc-induced copper deficiency: a report of three cases initially recognized on bone marrow examination. Am J Clin Pathol 2005; 123:125-31

16. Ruocco L, Baldi A, Cecconi N, et al. Severe pancytopenia due to copper deficiency. Case report. Acta Haematol 1986; 76:224-6

17. Wasa M, Satani M, Tanano H, et al. Copper deficiency with pancytopenia during total parenteral nutrition. JPEN J Parenter Enteral Nutr 1994; 18:190-2

18. Spiegel JE, Willenbucher RF. Rapid development of severe copper deficiency in a patient with Crohn's disease receiving parenteral nutrition. JPEN J Parenter Enteral Nutr 1999; 23:169-72

19. Fuhrman MP, Herrmann V, Masidonski P, et al. Pancytopenia after removal of copper from total parenteral nutrition. JPEN J
Parenter Enteral Nutr 2000; 24:361-6

20. Bartner R, Will M, Conrad J, et al. [Pancytopenia, arthralgia and myeloneuropathy due to copper deficiency]. Med Klin (Munich) 2005; 100:497-501

21. Hoffman HN, 2nd, Phyliky RL, Fleming CR. Zinc-induced copper deficiency. Gastroenterology 1988; 94:508-12

22. Kumar A, Jazieh AR. Case report of sideroblastic anemia caused by ingestion of coins. Am J Hematol 2001; 66:126-9

23. Fessatou S, Fagerhol MK, Roth J, et al. Severe anemia and neutropenia associated with hyperzincemia and hypercalprotectinemia. J Pediatr Hematol Oncol 2005; 27:477-80

24. Ramadurai J, Shapiro C, Kozloff M, et al. Zinc abuse and sideroblastic anemia. Am J Hematol 1993; 42:227-8

25. Irving JA, Mattman A, Lockitch G, et al. Element of caution: a case of reversible cytopenias associated with excessive zinc supplementation. CMAJ 2003; 169:129-31

26. Gregg XT, Reddy V, Prchal JT. Copper deficiency masquerading as myelodysplastic syndrome. Blood 2002; 100:1493-5

27. Kumar N, Ahlskog JE, Gross JB, Jr. Acquired hypocupremia after gastric surgery. Clin Gastroenterol Hepatol 2004; 2:1074-9

28. Hayton BA, Broome HE, Lilenbaum RC. Copper deficiencyinduced anemia and neutropenia secondary to intestinal malabsorption. Am J Hematol 1995; 48:45-7

29. Todd LM, Godber IM, Gunn IR. Iatrogenic copper deficiency causing anaemia and neutropenia. Ann Clin Biochem 2004; 41:414-6

30. Hedera P, Fink JK, Bockenstedt PL, et al. Myelopolyneuropathy and pancytopenia due to copper deficiency and high zinc levels of unknown origin: further support for existence of a new zinc overload syndrome. Arch Neurol 2003; 60:1303-6

31. Hirase N, Abe Y, Sadamura S, et al. Anemia and neutropenia in a case of copper deficiency: role of copper in normal hematopoiesis. Acta Haematol 1992; 87:195-7.

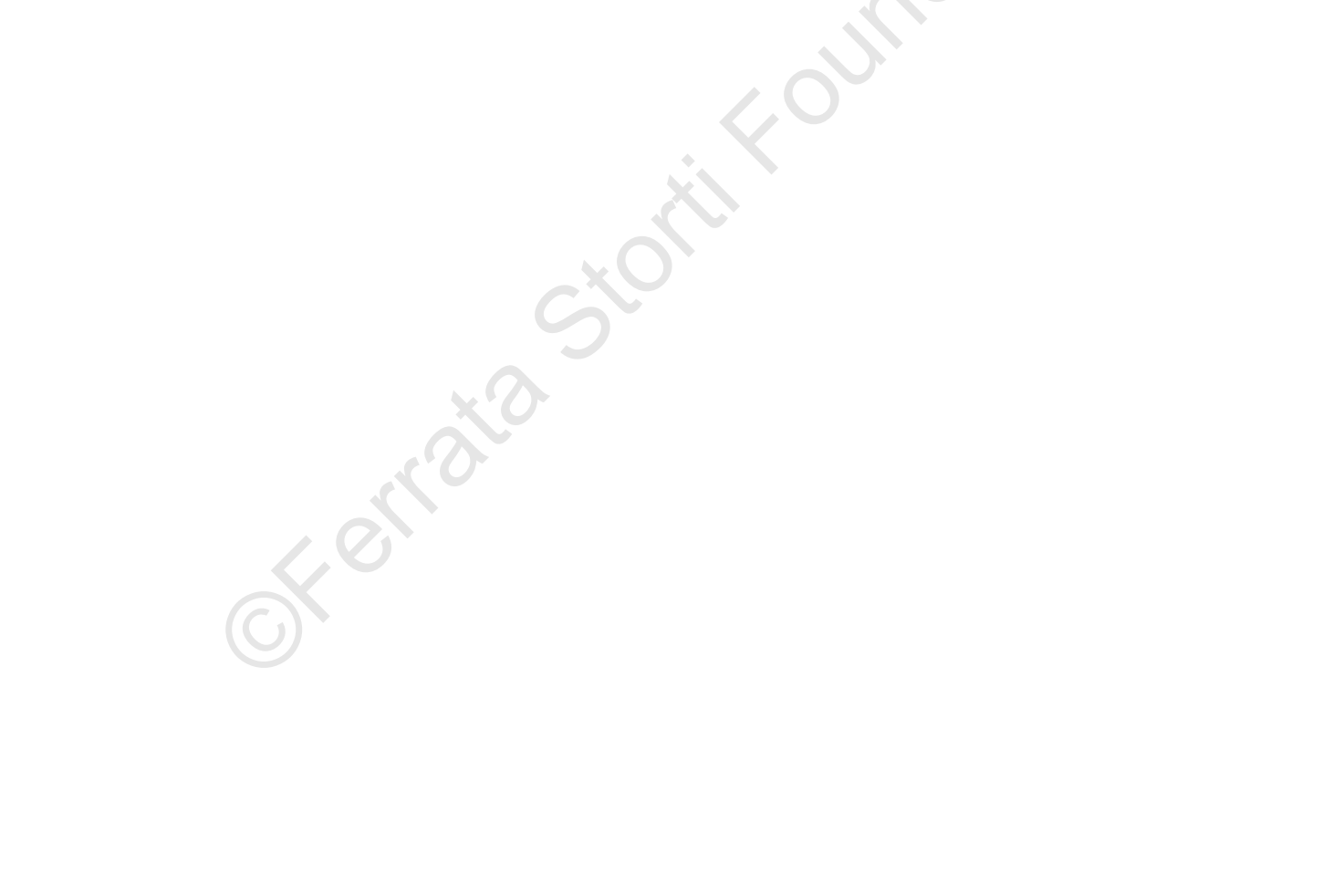

